\title{
LA-UR-97- 2215
}

Title:

Expedited Site Characterization

Author:

Iain McCreary

Steven R. Booth

Energy and Environmental Analysis (TSA-4)

Submitted to:

\section{General Distribution}

March 1997 DISTRIBUTION OF THIS OOCUMENT IS UNLMITED

\section{DISCLAIMER}

This report was prepared as an account of work sponsored by an agency of the United States Government. Neither the United States Government nor any agency thereof, nor any of their employees, makes any warranty, express or implied, or assumes any legal liability or responsibility for the accuracy, completeness, or usefulness of any information, apparatus, product, or process disclosed, or represents that its use would not infringe privately owned rights. Reference herein to any specific commercial product, process, or service by trade name, trademark, manufacturer, or otherwise does not necessarily constitute or imply its endorsement, recommendation, or favoring by the United States Government or any agency thereof. The views and opinions of authors expressed herein do not necessarily state or reflect those of the United States Government or any agency thereof.
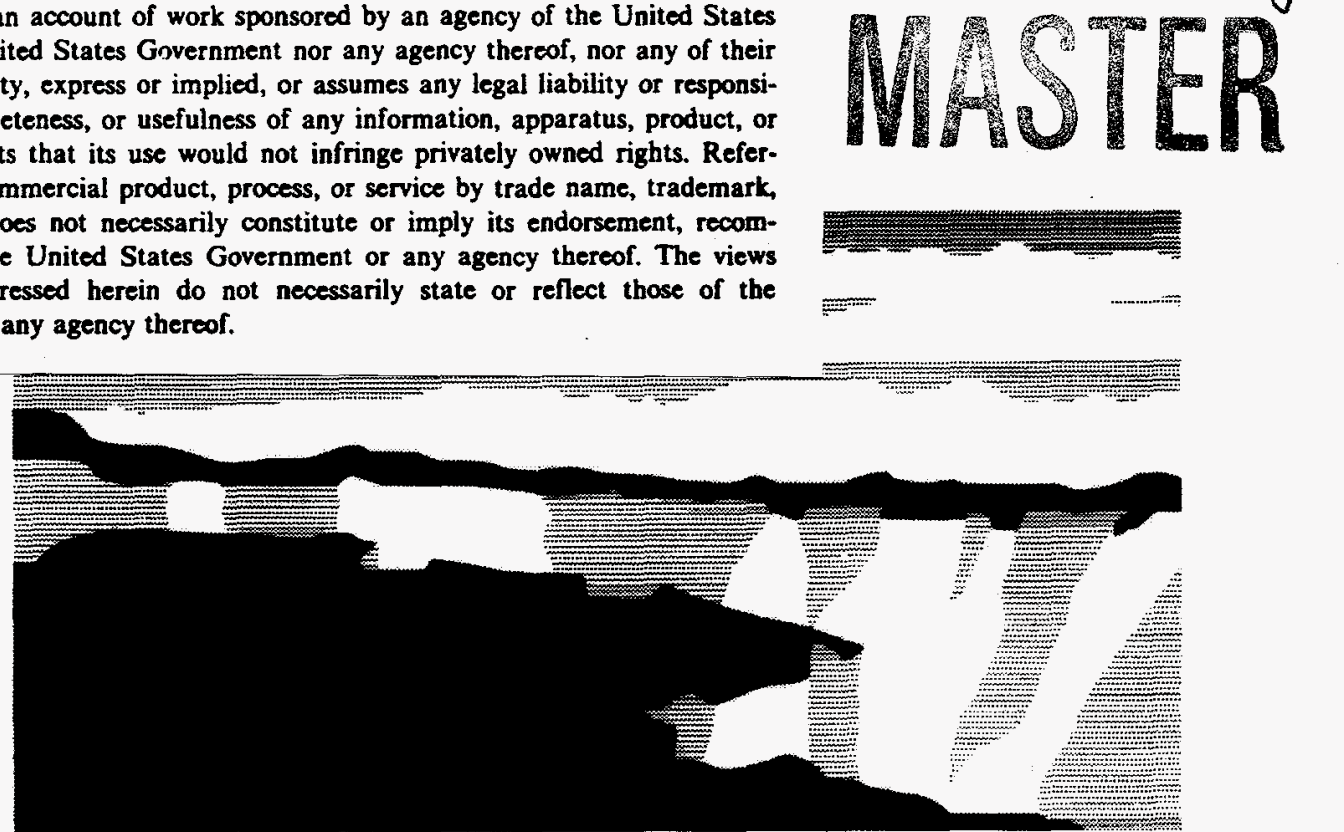

NATIONAL LABORATORY

Los Alamos National Laboratory, an affirmative action/equal opportunity employer, is operated by the University of California for the U.S. Department of Energy under contract W-7405-ENG-36. By acceptance of this article, the publisher recognizes that the U.S. Government retains a nonexclusive, royalty-free license to publish or reproduce the published form of this contribution, or to allow others to do so, for U.S. Government purposes. The Los Alamos National Laboratory requests that the publisher identify this article as work performed under the auspices of the U.S. Department of Energy. Los Alamos National Laboratory strongly supports academic freedom and a researcher's right to publish; therefore, the Laboratory as an institution does not endorse the viewpoint of a publication or guarantee its technical correctness. 


\section{DISCLAMIER}

Portions of this document may be illegibie in electronic image products. Images are produced from the best available original document. 


\section{Contents}

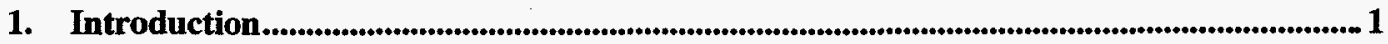

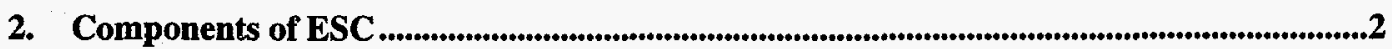

3. Cost Comparison of ESC to Traditional Methodologies...............................................3

3.1 Example: A Case Study of ESC at DOE's Pantex Plant............................................5

4. ESC Versus Other Streamlined Characterization Methodologies....................................... 8

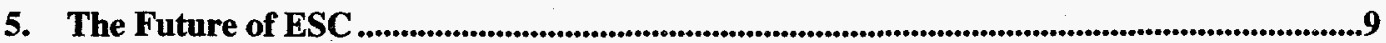

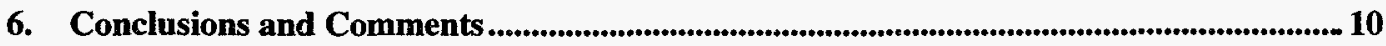

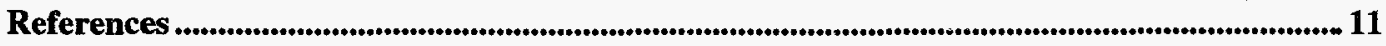

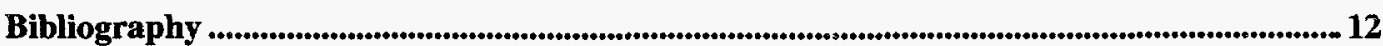

\section{Tables}

Table 1. ESC labor savings as calculated by Argonne.......................................................4 4

Table 2. ESC may offer no cost savings in labor.

Table 3. Post phase I penetrations at Pantex ..........................................................................66

Table 4. Hypothetical costs for ESC versus traditional methods at Pantex. ............................. 7

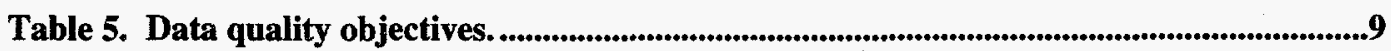

Table 6. Possible steps to include DQO in the ESC method................................................. 10 


\section{Introduction}

Expedited Site Characterization (ESC) is being offered as a new, more cost-effective way to perform DOE environmental site characterizations. Site characterization of environmental cleanup sites can be costly and time consuming. "Traditional techniques," though effective, are the outgrowth of cautious and often restrictive regulatory control. At some sites up to $40 \%$ of the funds and 70\% of the time spent on cleanup operations have been devoted to characterization [1]. More realistically, the DOE's Ten Year Plan (TYP) Cost Rollup by Category (high budgetary version) budgets $\$ 1.34$ billion to remedial action assessments out of a total of $\$ 9.7$ billion in remedial actions - about $14 \%$ of the total TYP expenditures for this type of cleanup work [2]. The expenditure percentage for characterization drops to a much lower $3 \%$ of total expenditures during outyears, after 2006, as most of the assessments will have been completed during the early TYP years. (The sampling and monitoring costs, however, rise from $7 \%$ of the budget during the TYP to $30 \%$ during the outyears as this activity continues and others decline. Improved characterizations could have the potential to reduce the need for some of these ongoing monitoring costs.)

Fortunately, regulatory agencies have begun to relax many of the constraints on site characterization allowing more efficient and innovative approaches to be applied. Argonne National Laboratory's Expedited Site Characterization is perhaps the best defined of these new approaches. ESC is founded on the premise that it is cheaper, faster, and more efficient to develop and test a conceptual model (or "hypothesis") of contamination at a site than it is to collect data on a statistical basis and then attempt to model a site from those data. The difference between these two approaches has been described as a "scientific versus an engineering approach." ESC creates and then tests a hypothesis with a minimum of sampling, while more traditional methods rely on an abundance of collected data to deterministically model a site. The choice of a characterization method is not always straight forward. Though faster, ESC requires considerable, coordinated scientific expertise to create the hypothesis and evaluate the data in the field. And while the traditional approach typically yields more data, testing and sampling can continue for years before delivering an accurate and reliable model.

In terms of cost savings, the difference between ESC and traditional methods lies in execution. Where traditional methods might call for a 100 sampling soil penetrations in a grid around a suspected contaminant plume location, the new approach would essentially rely on the expertise of an experienced field team to make an educated guess where the plume was and then make a greatly reduced number of penetrations to define it. For example, in the Pantex case study, the ESC approach used a total of 25 penetrations (soil sampling holes and completed wells, 11 of which existed at start up). The planned traditional approach called for 54 total penetrations. The total savings from implementing the ESC approach amounted to $\$ 6.8$ million. 


\section{Components of ESC}

ESC is not a technology, but an analysis philosophy. The goal is the fastest, cheapest, and most efficient site characterization possible. ESC is meant to be flexible and the components of ESC as listed here should be considered guidelines, rather than fixed rules [ 3 - for complete detail].

To implement an efficient ESC approach, three things are needed. These are:

1) the technical expertise to develop and test a hypothesis (site conceptual model),

2) the tools to analyze and interpret the data, and

3) the authority to redirect testing and sampling resources as required.

The scientific and technical expertise is supplied in the form of a team of senior level scientists (typically 3 to 4 individuals with expertise in geologic, hydrologic, and chemical systems appropriate to the site with a designated team leader). Senior staff are used, despite the added cost, to ensure that sufficient technical knowledge is available on site. Implementation of the ESC process as listed by Argonne [4] involves the following steps.

\section{ESC Process Summary}

1. Technical manager and science team selected

2. Team evaluates existing site data (critical site review)

3. Site visit -- team develops initial hypothesis (conceptual model)

4. Selection of sampling/testing technologies appropriate to test hypothesis

5. Course of action proposed (dynamic work plan)

6. Team deployed

7. Work begins -- data collected and analyzed daily, hypothesis (conceptual model) and work plan updated as necessary

8. As soon as modified hypothesis is verified, characterization documents are submitted

Although the basic principle is one of applied common sense, the key to ESC is that a hypothesis or conceptual model is proposed, then tested through data development, and the model and data-gathering plans immediately modified based upon field results. This requires that the team have sufficient technical knowledge and field experience to interpret the data and modify the work plan according to changing needs. The actual on-the-ground sampling is altered as the hypothesis gets modified. Only sampling that contributes to new understanding is undertaken. Team expertise must include not only knowledge of geology and the fate and transport of contaminants, but also of the available diagnostic technologies so that the field tests which are being used are appropriate to the questions which are being asked.

The key advantage of the ESC process lies in its characteristic of having rapid data analysis and integration. This garners high value from experienced, expensive professionals by requiring 
their presence in the field for only a short time, making intelligently guided changes in data development efforts, and minimizing expensive fruitless on-the-ground work.

\section{Cost Comparison of ESC to Traditional Methodologies}

A generic cost comparison of ESC to traditional methods is difficult because characterization problems/campaigns are site specific. ESC relies on the team expertise to know which method is the cheapest and most efficient way to address a given problem. ESC can be broken down into two major cost components, labor and sampling.

ESC labor costs, as well as traditional labor costs, are probably relatively stable and similar to each other in that the needs for various expertise/skills and the amount of time spent in thought and analysis imposes minimum requirements to address a specific category of characterization problem. A typical ESC team may be composed of 3 to 4 senior scientists, versus a traditional team of 1 senior level leader with 3 to 4 assistants. The average ESC team member, as defined in early protocols for ESC operations, is quite senior and higher paid than a traditional team member [3]. Therefore, ESC costs per team per time period are higher, but are expected to be employed for quite a bit less time. Analyses of case studies published seem to indicate that this cost difference is likely minimal with no overwhelming labor cost advantage to either system of analysis. Of course, actual team membership requirements in both cases are highly site specific and likely to be highly variable across differing sites and differing characterization problems. What is likely to be stable across team makeups is the total intellectual activity that goes into data analysis and conceptual development. Assuming quality end-product characterizations, roughly equivalent amounts of intellectual analyses will have been expended to get to roughly the same final state of characterization knowledge. The ESC system may have expended more intellectual energy in redirecting the flow of analytical work during the sampling campaign, whereas the traditional team would have had to put more energy into data analysis upon receipt of more voluminous data. The comparative cases studied published to date $[4,5,6,7]$ :

- do not document any dramatic cost savings or penalties attributable to labor cost differences between ESC and the traditional approach,

- are too limited in statistical scope to justify claiming significant systematic differences,

- are speculative as to what outcomes would have been produced had the alternative approach been used instead, and

- are best described as anecdotal rather than analytic.

Argonne projects overall savings in labor because an ESC team is expected to be employed for much less time (about half the time in one well-documented DOE case) than a traditional team. As calculated by Argonne [5], an ESC team of 5 scientists would cost $\$ 2.9$ million over 2.5 years, while a more traditional team would cost $\$ 3.3$ million over 4.5 years (Table 1). This difference comprises only a very small part of the overall ESC claimed savings in the referenced study. Minor changes in team membership could easily reverse the numerical savings -- as in Table 2 
showing the effect of requiring just one more ESC team member employee. Labor cost savings are uncertain and are not likely to be an important driver of comparative cost effectiveness.

\section{Table 1. ESC labor savings as calculated by Argonne.}

\begin{tabular}{|l|l|}
\hline ESC & 5 senior staff $* 2.5$ years $=\$ \mathbf{2 . 9}$ million \\
\hline Traditional & 1 senior staff +4 junior staff $* 4.5$ years $:=\$ \mathbf{3 . 3}$ million \\
\hline
\end{tabular}

Table 2. ESC may offer no cost savings in labor.

\begin{tabular}{|c|c|c|}
\hline $\begin{array}{l}\text { ESC team of } 5 \text { for } 2.5 \text { years } \\
\text { If one additional team member added }\end{array}$ & $\begin{array}{l}\$ 2.9 \text { million } \\
\$ 580,000\end{array}$ & \\
\hline & $\begin{array}{c}\$ 3.5 \text { million } \\
\text { ESC Labor Total }\end{array}$ & $\begin{array}{c}\text { \$3.3 million } \\
\text { Traditional Labor Total }\end{array}$ \\
\hline
\end{tabular}

ESC's real savings are in time reduction and less field sampling work. In the Argonne example cited here at DOE's Pantex site, ESC delivers results in roughly half the time of its counterpart, two years ahead of the traditional method's schedule. Generally, the ability to start remediation work sooner will result in an earlier remedy to the hazards that the cleanup is ultimately intended to redress (if budgetary authority is available to carry out the work) -- this is a good thing, but not easy to quantify in dollar value terms. In present value terms, this shortened budget profile can even be a negative to the cost savings calculus as earlier expenditures cost the government more in present value dollars. The matter of time saving is too nebulous to apply a rigorous cost savings analysis. Competing factors are:

- environmental and other policies will change over time with uncertain effects either increasing or decreasing future cleanup requirements and subsequent budgetary expenditures.

- regulatory creep has traditionally added more real costs as time proceeds.

- technological progress has typically lowered real costs as time proceeds.

Net cost effects of time savings are likely to be ambiguous and highly assumption-dependent.

Besides saving time, ESC is likely to require both fewer samples and fewer penetrations than a traditional approach. At DOE's Pantex site for instance, the ESC approach reduced total penetrations by 24 wells, at a total savings of $\$ 8.3$ million when compared to the proposed traditional method [6].

The conclusion to be drawn from these numbers is that although ESC offers ro significant savings in labor costs, considerable savings can be realized from a reduction in the volume of field work. Second-order-effect cost savings may be realized by reduced completion time. In both 
cases, savings are heavily dependent on individual site characteristics including the degree of contamination and geological complexity.

A final advantage often projected for ESC is the improved characterization outcome. Better characterizations described in a number of ESC anecdotes have resulted in cleanups not needing to be done, and therefore, in major overall program cost reductions by taking cleanup work scope off the table. These anecdotes provide good promotional material for the ESC methodology. But they are not taken from extensive or unbiased statistical series and are highly selective. Additionally, it is not clear that traditional characterization might not also ultimately have come to many of the same fortunate results -- or different, more fortunate results from a cost point of view.

Historically, improving "measurement techniques" in environmental remediation has often resulted in adding scope (and adding cost) because of the greater capability to measure and define the problems -- merely raising the regulatory standard. While better characterization ought to be a goal for the sake of integrity and better policy/management, in-and-of itself there is little useable evidence to suggest whether an improved understanding of cleanup problems will result in net additions or subtractions from subsequent remediation work requirements and costs in the aggregate:

\subsection{Example: A Case Study of ESC at DOE's Pantex Plant}

ESC has been implemented at several non-DOE sites $^{1}$ but as yet has not been adopted on a widespread basis within the Department of Energy. One large-scale test of ESC with DOE was at the Pantex Plant in Texas. At this site, previous characterization efforts had met with limited success because the contamination and hydrogeology are complex. Geological characteristics include a perched aquifer at a depth of 250 feet, and a 400 -foot-thick aquifer at a 450 -foot depth. At the time ESC was implemented, the US Army Corps of Engineers (COE) had spent 2 years and \$2.1 million completing the first of a proposed 4-phase comprehensive traditional characterization effort. The Army COE project, supplanted by ESC, was scheduled to last a total of 5 years and cost $\$ 11.9$ million.

Phase I of the Army COE effort included the drilling of 11 wells, and the proposed additional phases called tor 43 more. In contrast, the actual ESC method made only four soil borings (one of which was later turned into a well) and nine cone penetrometer pushes. Once the ESC team left the site, an additional 10 borings and 5 monitor wells were made to determine precisely what remediation efforts would be required to treat the contaminant plume.

\footnotetext{
${ }^{1}$ Though developed at a DOE National Laboratory, most ESC work has been done at Department of Agriculture sites.
} 
As discussed above, ESC cost savings come primarily from a reduction in ground penetrations. At Pantex, savings were considerable (Table 3). All told, the actual ESC investigation included 19 penetrations at a cost of $\$ 3.7$ million, $\$ 8.2$ million cheaper than the projected 54

Table 3. Post phase I penetrations at Pantex

\begin{tabular}{|l|c|c|}
\hline & $\begin{array}{c}\text { ESC } \\
\text { (Actual) }\end{array}$ & $\begin{array}{c}\text { Traditional } \\
\text { (Planned) }\end{array}$ \\
\hline Borings & 13 & 0 \\
Wells (perched aquifer) & 5 & 39 \\
Wells (Ogallala) & 1 & 4 \\
\hline \multicolumn{1}{|c|}{ Total Penetrations } & $\mathbf{1 9}$ & $\mathbf{4 3}$ \\
\hline
\end{tabular}
penetrations and $\$ 11.9$ million cost of the traditional method.

Table 3 lays out the reduction in penetrations at Pantex. Numbers in this table do not include the 11 wells drilled by the Army COE in either column, nor do they include the 9 cone penetrometer (CPT) pushes that took place midway through the ESC investigation. If the 11 Phase I wells are included, total penetrations for both methods would increase by 11 . This table shows that the ESC approach of drilling as few wells as possible to satisfy specific questions about the site conceptual model allowed the team to cut the number of additional penetrations by more than half (again, not including the 11 wells in Phase I).

Previous examination of ESC performance at Pantex included expenses for the 11 Phase I wells in the traditional method costs, but did not include them in the ESC costs [6]. Here we assume that ESC used the results of the Army COE Phase I work, so to exclude all of the Army COE Phase I expenses from the ESC costs would seem unfair. Table 4 explores a hypothetical situation in which ESC is compared to the traditional method as if the Army COE Phase I results were not available. This makes a level comparison by adding hypothetical Phase I costs to the ESC total. An assumption is made that the ESC approach would have required 6 penetrations (less than the 11 wells actually drilled by the Army COE) and added an additional 4 months to the project lifetime. ${ }^{3}$ When these costs are included, the ESC investigation costs increase from $\$ 3.7$ to $\$ 5.1$ million, while the traditional costs remain unchanged at $\$ 11.9$ million. Still a considerable savings for ESC, but not so large a one as previously reported.

${ }^{2}$ These numbers differ from Tom Starke's Cost analysis of ESC at Pantex [6]. The reference study does not include CPT pushes in total penetrations (which increases the ESC total cost) and does include the existing 11 wells from the Army COE Phase I. CPT pushes have been included and the Phase I wells excluded here to keep the comparison between techniques level.

${ }^{3}$ Phone conversations with LANL and Argonne personnel [8]. 


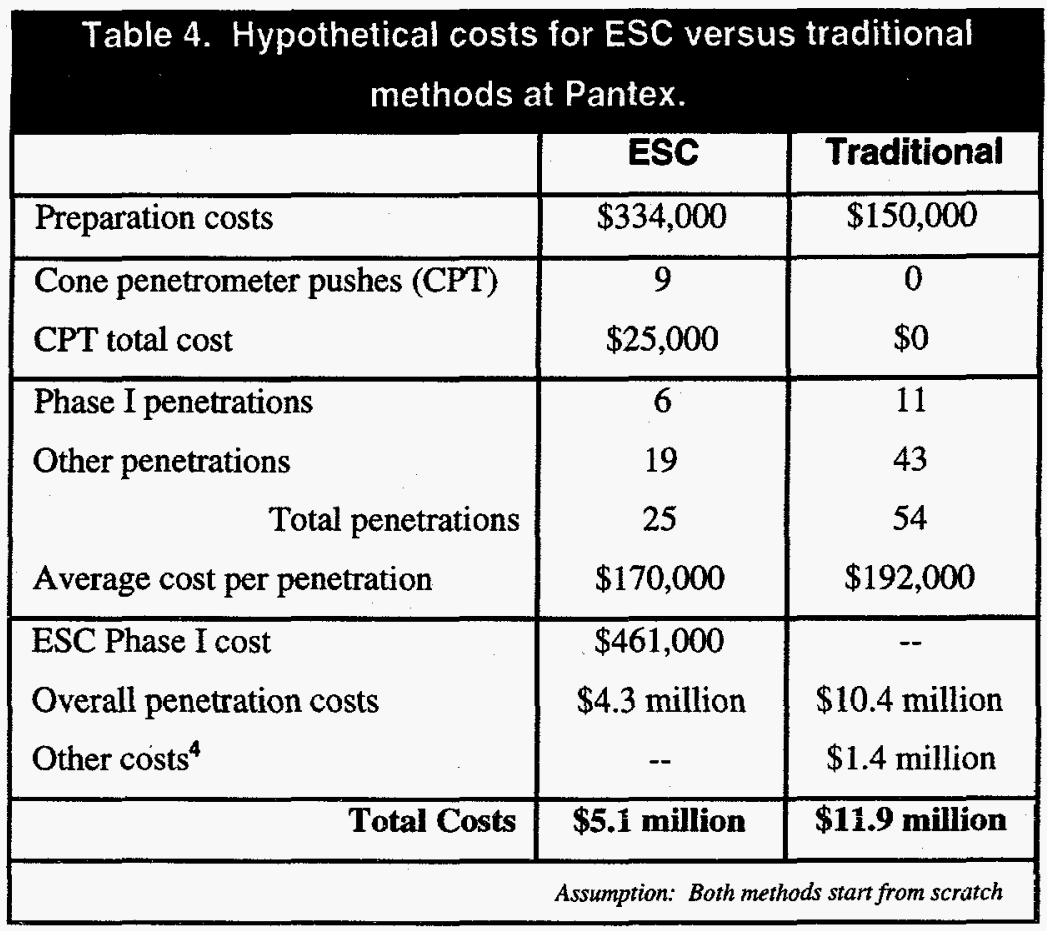

The breakdown of costs are briefly described in Table 4. Preparation costs for the two methods are different because the ESC approach requires a significant analytical effort by the ESC team to prepare a conceptual model (the hypothesis) before visiting the site. As the traditional method did not use this approach, its preparation costs were less at $\$ 150,000$ for the Army COE and $\$ 334,000$ for ESC. The next set of costs relates the CPT costs incurred in the ESC investigation. The ESC team made 9 CPT pushes at a total cost of $\$ 25,000$. The traditional method made no CPT tests and so incurred no costs in this section. Phase I penetrations include the 11 actual wells drilled by the Army COE for the traditional method, and the 6 hypothetical Phase I wells that are estimated the ESC team would require to obtain a similar amount of data. Other penetrations include the 19 actual wells and soil borings made by the ESC team and the 43 proposed but never implemented wells called for in the traditional method proposal. Total penetrations are the sum of the Phase I and other penetrations, 25 for ESC and 54 for the traditional method. Costs per penetration for each approach are calculated from the actual costs incurred at the site, including labor for both the contractors and the science teams. The ESC costs per penetration are slightly lower because ESC made 13 soil borings but only 6 actual wells, while the traditional approach called for 54 actual wells. The other costs data represents nonpenetration related costs incurred by the traditional approach. The totals for this hypothetical base comparison of the two methods is listed under Total Costs (Table 4). These estimated costs indicate that ESC

${ }^{4}$ Simplification of the cost breakdown in this table omits $\$ 1.1$ million of other costs spread out over 5 years for the traditional method. To keep the table simple, they have been listed here simply as other costs (senior staff costs valued at $\$ 120$ per hour, junior staff costs valued at $\$ 60$ per hour). 
offers a $57 \%$ savings in cost and a $40 \%$ reduction in characterization time as implemented at Pantex.

These numbers should not be taken too seriously. The example is intended to show only that significant cost savings can be attributed to the ESC methodology in a particular, real DOE remediation case. The assumptions used to derive the numbers could have taken on many different forms and are subject to almost endless speculation and interpretation. There is wide quantitative disagreement about these results on the part of Argonne, the Army COE, and LANL internal reviewers. This report's assumptions and results fall in the middle ground numerically. Each party has different ideas about what assumptions should be used and what the outcome would have been had the Army COE continued their traditional process. This is likely to be the case where one methodology is used in lieu of another, so that the unused methodology never gets a real chance to demonstrate how it would have proceeded and what it would have accomplished under the identical circumstances. Better quantification of ESC's average cost savings advantages must await a longer experience record so that statistical comparisons can be developed within reasonable confidence levels.

\section{ESC Versus Other Streamlined Characterization Methodologies}

Expedited Site Characterization is not the only streamlined characterization methodology in use. Many commercial operators and even some other federal laboratories have developed similar approaches. The question then becomes "Is ESC the best approach?" There are three areas where the ESC approach may face difficulties within particular jurisdictions. These are interaction with regulatory agencies, contractor bidding, and site applicability.

The ESC methodology [3] does call for regulatory interaction, but regulatory agents are not bound by the recommendations of the ESC approach. It is a major step for a regulating agency to move from approving the traditional, task-oriented milestones (number of sampling wells, etc.) to approving the more dynamic approach of ESC. ESC relies on the judgment of its team members to characterize the site properly, and this requires that the regulators also trust the team's judgment. Time must be taken to be sure the regulators fully understand both the process and techniques to be employed. Then reliance on the good will of the regulatory agents must prove to be justified in differing jurisdictions.

A second potential problem area is contractor bidding. ESC is a flexible tool, but it is so flexible that the total number of sampling penetrations to be applied at any given site is unknown until project completion. This may make it difficult for contractors to bid effectively. It is possible that ESC contractor bids should be made on a per-penetration basis for any given technique, rather than on a site total. Alternatively, minimum sampling requirements could be settled with the regulatory agency, and the contractors could bid on these minimum jobs with a negotiated additional per-well or per-penetration cost. This is an issue which should disappear 
with increasing experience and the development of a mature management system for ESC projects.

Lastly, the ESC approach as laid out by Argonne may not be applicable to all sites. Some sites with minor contamination or trivial analytical requirements may not require a full blown characterization effort. Further, the cleanup budget at some sites might not support a full ESC team. In such instances, a modified ESC approach could be used, with a one- to two-person team operating for shorter times. On some sites of minimal contamination the frontal assault of an ESC approach may not necessary. Or in cases where the regulators may require long-term statistical monitoring of the site, a traditional approach involving grid-spaced monitoring wells may be more suitable. It will continue to be necessary to assess the administrative and technical needs of each particular site before implementing the ESC methodology.

\section{The Future of ESC}

Many of ESC's competitors among the streamlined characterization methodologies utilize a formalized thinking process called Data Quality Objectives (DQO). ${ }^{5}$ DQO is a managerial tool which is used to lay out precisely which questions need to be answered, and how much data are needed to answer them (Table 5). Once a question is answered to the agreed upon DQO standard, inquiry into that subject is halted. Again, as with ESC's basic concept, DQO is little more than applied common sense -- once a question is answered, stop asking it.

\section{Table 5. Data quality objectives.}

1. Identify questions to be addressed

2. Determine data requirements to address questions and no more

3. Collect data

Instead of a formalized DQO approach, ESC is more subjective. Argonne relies on the science team's experience to determine when a question has been answered sufficiently, and it relies on the team's integrity to save money and close off avenues of investigation once a matter is settled. If ESC is adopted on a large scale, it might prove wise to formalize that sort of decision making (Table 6). If a DQO decision making approach were integrated into the ESC protocols, it could be used as a quantitative progress measure. This could be useful in "selling" an ESC project to a regulator. A more quantitative approach of a DQO plan would allow the regulators to set performance benchmarks for the ESC process, and in doing so perhaps make regulatory approval easier to obtain.

${ }^{5}$ Alternative methodologies include: DOE's Field Assessment Screening Team (FAST), McLaren Hart's Accelerated Investigation Method (AIM), and Neptune's Field Decision Support (FDS). Some of these are technology specific (FAST is for use in field lab testing at drilling sites) but all take an approach similar to ESC in that decision making is done in the field by a technically knowledgeable team or crew. 


\section{Table 6. Possible steps to include DQO in the ESC method.}

1. Discuss contaminant issues with regulators

2. Reach agreement with regulators on which questions rnust be addressed and their criterion for characterization

3. Engage in contractor bidding

4. Begin site characterization (ESC)

\section{Conclusions and Comments}

Expedited Site Characterization has the potential to be a cost-effective methodology. In comparison to traditional characterization methods, ESC appeared to offer time and cost savings of about 50\% in the Pantex characterization example. As implemented at DOE's Pantex plant, a start-to-finish ESC implementation ${ }^{6}$ was estimated to cost $\$ 5.1$ million over 3 years. This represents a savings of $57 \%$ in cost and a $40 \%$ reduction in time over traditional methods. ${ }^{7}$

Though significant, such savings are considerably less than the $80 \%$ to $90 \%$ potential cost reductions quoted by other studies by Argonne. ${ }^{8}$ Argonne projected these larger savings with ESC at Department of Agriculture sites, but those sites are remarkably different from DOE properties in both geological and contaminant composition. It may be the increased complexity of the DOE sites, in the Pantex example, which caused the relative cost savings of the method to be diminished. Better quantification of ESC's average cost savings advantages must await a longer experience record so that statistical comparisons can be developed within reasonable confidence levels.

Nevertheless, ESC's common sense approach to characterization is a much needed step toward efficient DOE cleanup operations. The approach has demonstrated its veracity to such an extent that it has already been designated for use in all future Savannah River Plant investigations and is written into Westinghouse's contract as an award fee item at that site.

The formalization of an ESC approach as described herein and in the references codifies a common sense approach to better characterization work. This is a valuable contribution to DOE's environmental management activities.

Those with long-term experience with site characterizations believe that to some extent ESC is an incorporation of sensible work approaches that have been a part of characterization work in the mining industry for many years. It has always been desirable to have a team of senior experts

\footnotetext{
${ }^{6}$ This is an estimated value as implemented at Pantex. ESC relied on data from a $\$ 2$ million Army COE study.

${ }^{7}$ These savings of roughly 50\% cost and 50\% time are corroborated by Reference 4 which comes to the following conclusion: "A more conservative approach (than the 5:1 cost reduction enjoyed by ESC at the USDA Murdock, Nebraska site) might be taken when comparing the different methods... Based on the qualitative aspects... a cost savings of about $50 \%$ and possibly a time savings of $50 \%$ should be considered."

${ }^{8}$ Eighty percent cost reductions were realized by an ESC approach at the Department of Agriculture CCC (USDA) site in Murdock, Nebraska. Savings at this level are also quoted in Reference 7.
} 
concentrate their efforts as a characterization team -- and direct and redirect activities at a site on an intensive, tightly coordinated schedule. It has also typically presented organization and management problems. It has been very difficult to coordinate these senior people's time with competing demands to make it all happen smoothly. A frequent compromise has been to order more penetrations with less immediate oversight -- thus the traditional method that ESC presumably replaces [9]. It should not be lost sight of that this compromise is typically made on sound economic grounds -- it is not inherently a poor choice given the coordination and management problems (and shadow costs) associated with alternatives -- it is usually the best choice available. In most cases it is chosen as the most cost-effective way to accomplish the work within the real world constraints of personnel and equipment availability. Any exploratory investigation, such as site characterization, involves uncertainty in work progress, and a strictly deterministic engineering approach to work design is inherently unworkable. Thus operational/management compromise always enters into the process and no rigid protocol is likely to be definable as being the "best."

The draft ASTM protocol, Guide for Expedited Site Characterization of Hazardous Waste Contaminated Sites [3], appears to be an excellent start at introducing common sense, costeffective approaches into DOE site characterizations. It provides desirable flexibility and forces recognition that concentrated, coordinated intellectual input is likely to have significant costsavings potential to DOE's environmental cleanup projects. The target for cost savings is the TYP budget of $\$ 1.34$ billion for characterization work. If the Pantex ESC example is at all representative, then its $50 \%$ savings translates into possible DOE complex-wide savings of $\$ 600$ 700 million through the year $2006 .^{9}$ ESC is a valuable concept. By formalizing and recognizing it, DOE may accelerate its own movement toward a more common sense cost effectiveness in site characterization.

\section{References}

1. Mark D. Nickelson, Delmar D. Long, "Field Assessment Screening Team (FAST) Technology Process and Economics," in Proceedings of the 27th Mid-Atlantic Industrial and Hazardous Waste Conference (no date).

2. DOE's Ten Year Plan (TYP) Cost Rollup by Category, Report ID D03, unpublished summary (March 1997).

3. "Guide for Expedited Site Characterization of Hazardous Waste Contaminated Sites," ASTM Committee D-18, D18.01.01 Task Group, Draft No: 6.0 (February 24, 1997).

4. "Expedited Site Characterization (ESC) Scoping Cost Savings Analysis," Argonne National Laboratory report (no report number or date).

5. Jacqueline C. Burton, "Expedited Site Characterization for Remedial Investigations at Federal Facilities," Argonne National Laboratory report ANL-ER-CP-81933 (no date).

\footnotetext{
${ }^{9}$ In characterizing ESC's potential savings to the DOE cleanup baseline expenditure estimates, it may be more appropriate to consider them in the category of management improvements rather than as the result of technology development.
} 
6. Thomas P. Starke, "Cost Effectiveness Analysis of Expedited Site Characterization at the DOE Pantex Plant," Los Alamos National Laboratory report LA-UR-96-2945 (no date).

7. Jacqueline C. Burton, et. al., "Expedited Site Characterization: A Rapid Cost Effective Process for Preremedial Site Characterization," Superfund XIV Conference and Exhibition Proceedings-Volume II (1993).

8. Dr. Tim Meyer, Argonne National Laboratory, ESC team leader, Argonne, IL, personal communication (February 1997).

9. Dr. Ed Van Eeckhout, Los Alamos National Laboratory, Los Alamos, NM (formerly Professor, Mining Dept., Montana Tech, Butte, MT) personal communication (May 1997).

\section{Bibliography}

Jacqueline C. Burton, "Prioritization to Limit Sampling and Drilling in Site Investigations," Argonne National Laboratory report (no report number or date). 